\title{
Genetic disruption of multidrug resistance-associated protein 1 improves endothelial function and attenuates atherosclerosis in MRP1 ${ }^{-/-} \mathrm{LDLr}^{-/-}$double knockout mice
}

\author{
Julian Jehle, Cornelius F. H. Müller, Adem Aksoy, Sebastian Zimmer, Georg Nickenig, Vedat Tiyerili
}

Klinik II für Innere Medizin, Universität Bonn, Bonn, Germany

Submitted: 13 July 2016

Accepted: 8 December 2016

Arch Med Sci 2017; 13, 4: 930-936

DOI: https://doi.org/10.5114/aoms.2017.68239

Copyright @ 2017 Termedia \& Banach

\section{Abstract}

Introduction: Multidrug resistance-associated protein 1 (MRP1) is an anion transporter which is implicated in the efflux of the intracellular antioxidant anion glutathione as well as leukotrienes. Pharmacological inhibition of MRP1 exhibits antioxidative and anti-atherosclerotic effects both in vitro and in vivo. However, pharmacological inhibitors of MRP1 lack selectivity, which prompted us to study the in vivo impact of a genetic disruption of MRP1 on endothelial dysfunction, reactive oxygen species formation and atherogenesis in an atherosclerotic mouse model.

Material and methods: MRP1 $1^{-/} \mathrm{LDLr}^{--}$double knockout mice. were fed a high-fat and cholesterol-rich diet for 7 weeks. Thereafter, endothelial function was assessed in isolated aortic rings. Reactive oxygen species were quantified by L-012 chemiluminescence, and the atherosclerotic plaque burden was measured following oil red $\mathrm{O}$ staining.

Results: Endothelium-dependent vasodilation of $\mathrm{MRP}^{-/-} \mathrm{LDLr}^{--}$double knockout mice was significantly improved compared to MRP1-competent LDLr $^{-1}$ single knockout mice $(0.56 \pm 0.06$ vs. $0.78 \pm 0.08 ; n=10 ; p=0.048)$. This improvement was accompanied by a significant reduction in reactive oxygen species formation within the aortic tissue $(102 \pm 27 \mathrm{RLU} / \mathrm{s} / \mathrm{mg}$ vs. $315 \pm 78 \mathrm{RLU} / \mathrm{s} / \mathrm{mg}, n=9-11, p=0.03)$. Moreover, the atherosclerotic plaque burden of $\mathrm{MRP}^{-/-} \mathrm{LDLr}^{-1}$ double knockout mice was significantly reduced $(0.06 \pm 0.01$ vs. $0.12 \pm 0.02 ; n=6 ; p=0.047)$. Finally, arterial blood pressure was significantly reduced in $\mathrm{MRP}^{1 /-} \mathrm{LDLr}^{-1}$ double knockout mice $(93 \pm 5$ $\mathrm{mm} \mathrm{Hg}$ vs. $128 \pm 4 \mathrm{~mm} \mathrm{Hg} ; n=8-12 ; p<0.001)$.

Conclusions: Genetic disruption of MRP1 appears to reduce blood pressure and vascular oxidative stress in vivo, which leads to improved endothelial function and a reduced plaque burden in atherosclerotic mice. Therefore, MRP1 might represent a promising therapeutic target to improve endothelial function in patients suffering from atherosclerosis.

Key words: reactive oxygen species, multidrug resistance-associated protein 1, arterial blood pressure.

\section{Introduction}

Reactive oxygen species (ROS) production is a driving mechanism of atherogenesis. A vast body of both animal and human studies has linked cardiovascular risk factors to ROS production, which, in turn, causes endothelial activation, dysfunction and apoptosis, lipid oxidation and activation of matrix metalloproteinases (reviewed in [1-3]) - all hallmarks of atherosclerosis. Mitigation of ROS is accomplished by antioxidant

\author{
Corresponding author: \\ Julian Jehle \\ Klinik II für Innere Medizin \\ Universität Bonn \\ Sigmund-Freud-Straße 25 \\ 53127 Bonn, Germany \\ Phone: +4922828751484 \\ Fax: +49 22828751482 \\ E-mail: julian.jehle@ukb. \\ uni-bonn.de
}


agents, such as glutathione peroxidase (GSHPx), which uses glutathione (GSH) for a redox partner (reviewed in [4]). Thus, regulation of cellular GSH homeostasis is crucial to cellular defence against oxidative stress and to the prevention of atherogenesis.

GSHPx catalyses the reduction of hydroperoxides into their respective alcohols, while GSH is oxidised into glutathione disulfide (GSSG) [4]. In order to maintain cellular redox balance, GSSG needs to be reduced back to GSH or has to be excreted from the cell. The latter requires active transport by multidrug resistance protein 1 (MRP1, $A B C C 1$ ), which is a member of the ATP-binding cassette family and which exhibits a high affinity not only to GSSG but also to GSH and proinflammatory GSH conjugates such as leukotriene $\mathrm{C}_{4}\left(\mathrm{LTC}_{4}\right)$ [5-8]. Excretion of GSH and GSSG, however, leads to a diminished cellular thiol pool, which causes an excess of ROS and impairs endothelial function [9].

The relevance of MRP1 to endothelial function and repair has already been demonstrated in various in vivo models: Genetic disruption of MRP1 has been shown to improve endothelial function in both DOCA-salt- and angiotensin II-induced hypertensive mice $[7,10]$, as well as in diabetes mellitus [11]. Moreover, MRP1 $1^{-1-}$ mice showed an increased number of both circulating and resident endothelial progenitor cells (EPCS), which caused improved re-endothelialisation following endothelial damage compared to wildtype controls [12].

In an atherosclerosis-prone mouse model, however, the impact of a genetic disruption of MRP1 on endothelial function and atherogenesis has never been investigated before. Yet, Mueller et al. were able to demonstrate that pharmacological inhibition of MRP1 by MK571 leads to improved endothelial function and to a reduced plaque burden in atherosclerotic ApoE-deficient mice [8]. MK571, however, does not selectively inhibit MRP1 but also blocks the proinflammatory leukotriene receptor CysLT1 at low nanomolar concentrations [13].

Nevertheless, the anti-atherogenic properties of MK571 encouraged us to generate an MRP1and low-density lipoprotein receptor- (LDLr) deficient double knockout mouse model (MRP1 ${ }^{-/-}$ $\mathrm{LDLr}^{--}$) in order to evaluate the significance of MRP1 to atherogenesis and to overcome the limitations of the previously used model of pharmacological MRP1 inhibition. Consequently, MRP1 $1^{-/}$ $\mathrm{LDLr}^{--}$double knockout mice were generated and were fed a high-fat and cholesterol-rich diet for 7 weeks. Afterwards, endothelial function, ROS production and atherosclerotic lesion formation were assessed. We hypothesized that MRP1-/$\mathrm{LDLr}^{-1}$ double knockout mice would exhibit improved endothelial function and a reduction in atherosclerotic plaque volume compared to $\mathrm{LDLr}^{--}$ single knockout mice.

\section{Material and methods}

$\mathrm{LDLr}^{--}$mice and $\mathrm{MRP}^{-/-}$mice, both of FVB origin, were purchased from Taconic (Hudson, USA) and crossed to obtain MRP1 ${ }^{-/-} \mathrm{LDLr}^{-1}$ double knockout mice. Successful homozygous disruption of the LDLr and MRP1 genes was verified by qualitative PCR and subsequent gel electrophoresis. $\mathrm{LDLr}^{-1}$ single knockout mice with an intact MRP1 gene were used as controls.

Animals were kept at $22^{\circ} \mathrm{C}$ room temperature and a 12-hour dark-light-cycle and had unrestricted access to drinking water and rodent chow. Treatment of laboratory animals was in accordance with institutional guidelines and German animal protection law. All experiments were approved of by the North Rhine Westphalian State Agency for Nature, Environment and Consumer Protection and the local ethics committee which is in charge of the University of Bonn.

Twelve-week-old mice were fed a high-fat and high-cholesterol diet for 7 weeks containing $21 \%$ fat, $19.5 \%$ casein, and $1.25 \%$ cholesterol (Ssniff, Soest, Germany). Upon completion of the feeding period mice were anesthetized with $5 \%$ isoflurane (Abbott Laboratories, Chicago, USA), and sacrificed by cervical dislocation.

\section{Endothelial relaxation}

Endothelial relaxation was assessed in isolated aortic rings as described earlier [14]. The descending thoracic aorta was transferred into $37^{\circ} \mathrm{C}$ warm buffer containing, in $\mathrm{mM}, \mathrm{NaCl} 118.0$, $\mathrm{CaCl}_{2}$ 2.5, $\mathrm{KCl}$ 4.73, $\mathrm{MgCl}_{2}$ 1.2, $\mathrm{KH}_{2} \mathrm{PO}_{4}$ 1.2, $\mathrm{NaHCO}_{3}$ 25.0, NaEDTA 0.026, D(+)glucose 5.5, adjusted to $\mathrm{pH} 7.40$. Adherent connective tissue was carefully removed and $3 \mathrm{~mm}$ thick rings were cut. These aortic rings were carefully hooked to a force transducer in an organ bath (IOA-5301, FMI GmbH, Seeheim, Germany), which was perfused by the above-mentioned buffer and aerated by oxygen. Aortic rings were preloaded with a force of $10 \mathrm{mN}$ and allowed to achieve their respective resting tension for $10 \mathrm{~min}$. Endothelial integrity was ascertained by measuring contractility upon administration of $40 \mathrm{mM}$ $\mathrm{KCl}$. Increasing concentrations of phenylephrine were administered up to a maximum concentration of $100 \mu \mathrm{M}$ to induce vasoconstriction. The maximum amplitude of vasoconstriction was calculated as the difference between the maximum tension and the resting tension. Vasodilation was then induced by administration of increasing concentrations of carbachol (maximum concentration $100 \mu \mathrm{M}$ ) and nitroglycerine 
(maximum concentration $10 \mu \mathrm{M}$ ) respectively. For each concentration, the amplitude of vasoconstriction was calculated as the difference between the resulting tension under the respective concentration of vasodilating agent and the resting tension. Vascular relaxation capacity was calculated as 1 - (respective amplitude of vasoconstriction/maximum amplitude of vasoconstriction). Vascular relaxation upon administration of carbachol was considered endothelium-dependent, while vascular relaxation upon administration of nitroglycerine was considered endothelium-independent.

\section{Reactive oxygen species formation}

The proximal and the distal end pieces of the descending thoracic aorta were used for the quantification of reactive oxygen species levels using the L012 chemiluminescence method as described [15]. L012 working solution was made up freshly immediately prior to use as follows: L012 stock solution (Wako Chemicals $\mathrm{GmbH}$, Neuss, Germany) was diluted in PBS by $1: 100$. The working solution was made up by adding $100 \mu \mathrm{l}$ of the diluted L012 solution to every $900 \mu$ of modified $\mathrm{KH}-\mathrm{HEPES}$-buffer, containing in $\mathrm{mM}$ : $\mathrm{NaCl}$ 99.01, $\mathrm{KCl} 4.69, \mathrm{CaCl}_{2}$ 1.87, $\mathrm{MgSO}_{4} 1.20$, NaHEPES 20.0, $\mathrm{K}_{2} \mathrm{HPO}_{4}$ 1.03, $\mathrm{NaHCO}_{3} 25.0, \mathrm{D}(+)$ glucose 11.1 , adjusted to $\mathrm{pH} 7.40$. Tissue samples were transferred into $200 \mu \mathrm{l}$ of the L012 working solution and chemiluminescence was assessed for $10 \mathrm{~min}$ at intervals of $1 \mathrm{~min}$ using a scintillation counter (Lumat LB 9501, Berthold Technologies GmbH \& Co. KG, Wildbad, Germany). The 5-minute value was used for statistical comparison of the two groups. L012 working solution without aortic tissue was measured to obtain blank values, which were subtracted from the 5-minute scintillation counts of tissue samples. Thereafter, the net scintillation count was normalised to tissue weight.

\section{Histological sections and quantification of plaque burden}

Hearts of MRP1 ${ }^{-/-} \mathrm{LDLr}^{--}$double knockout mice and $\mathrm{LDLr}^{-1-}$ controls were excised and embedded upright in tissue freezing medium. Following horizontal positioning of the aortic valve, hearts were snap frozen at $-80^{\circ} \mathrm{C}$ and allowed to freeze thoroughly for at least $24 \mathrm{~h}$. Then, tissue samples were sliced using a Leica CM 1900 cryostat (Leica Biosystems $\mathrm{GmbH}$, Wetzlar, Germany) at a thickness of $8 \mu \mathrm{m}$ per section and sections through the aortic sinus were recovered on Polysine Slides (Thermo Fisher Scientific, Inc., Waltham, USA).

Next, oil red staining of the frozen sections was performed to visualise atherosclerotic plaques as described [16]. $0.5 \mathrm{~g}$ of Oil red O (Sigma-Aldrich, St. Louis, USA) were dissolved in $100 \mathrm{ml}$ of isopropanol as a stock solution. Immediately prior to use, the oil red working solution was prepared by adding $20 \mathrm{ml}$ of deionised water to $30 \mathrm{ml}$ of the stock solution. Frozen sections were allowed to defrost and dry at room temperature. Then, sections were incubated in $4 \%(\mathrm{w} / \mathrm{v})$ paraformaldehyde in PBS for 45 min for fixation. Subsequently, slides were rinsed in deionised $\mathrm{H}_{2} \mathrm{O}$ for 10 min and dehydrated in $60 \%(\mathrm{v} / \mathrm{v})$ isopropanol for $5 \mathrm{~min}$. Next, slides were exposed to the oil red working solution for $15 \mathrm{~min}$, rinsed once more for $10 \mathrm{~min}$ in deionised $\mathrm{H}_{2} \mathrm{O}$ and costained with haematoxylin for $30 \mathrm{~s}$. Finally, slides were washed in lukewarm tap water for $15 \mathrm{~min}$ and stained slides were covered using Aquatex mounting agent (Merck Millipore, Darmstadt, Germany).

Microphotographic images were obtained from a Zeiss Axiovert 200M microscope (Carl Zeiss Jena $\mathrm{GmbH}$, Jena, Germany) using Axiovision 4.8 software (Carl Zeiss Jena $\mathrm{GmbH}$ ). Affiliation to the $\mathrm{MRP}^{-1-} \mathrm{LDLr}^{--}$double knockout group or to the control group was blinded prior to assessment. Oil red-stained areas were normalised to the size of the vessel wall.

\section{Body weight, plasma cholesterol and glucose levels, blood pressure and heart rate}

Body weight was assessed prior to and at the end of the feeding period using a Kern EW 3000$2 \mathrm{M}$ balance (Kern \& Sohn $\mathrm{GmbH}$, Balingen, Germany).

Plasma cholesterol levels were measured by gas chromatography-flame ionisation detection, as described earlier [15]. Fasting blood glucose levels were determined using a blood glucose meter (Accu-Chek, Roche Diagnostics Deutschland GmbH, Mannheim, Germany).

Blood pressure and heart rate were measured using a non-invasive Volume Pressure Recording system (Kent Scientific Corporation, Torrington, USA). Prior to recording, mice were allowed to accustom to the measurements on three consecutive days for $20 \mathrm{~min}$ each day. For this purpose, mice were placed in the restrainer and the tail cuff was positioned. Actual recording of the measurements was accomplished on the 3 consecutive days following the acclimatisation period.

\section{Quantification of GSH and LTC4 in murine plasma and abdominal aortic tissue}

GSH levels and LTC4 levels were quantified in both plasma and abdominal aortic tissue by a fluorometric assay for GSH (Abcam plc., Cambridge, UK) and by ELISA for LTC4 (Elabscience, Bethesda, USA) according to the manufacturer's instructions. 
Abdominal aortas of $\mathrm{MRP}^{-/-} \mathrm{LDLr}^{--}$double knockout mice and $\mathrm{LDLr}^{-1}$ controls were excised and rinsed in ice-cold PBS. Then, tissue samples were transferred into mammalian cell lysis buffer (Abcam plc.) and were ground using a Schuett homogen plus tissue lyser (Schuett-biotec $\mathrm{GmbH}$, Göttingen, Germany). Cell lysates were centrifuged for $15 \mathrm{~min}$ at $20,000 \times \mathrm{g}$ and $4^{\circ} \mathrm{C}$ and the supernatant containing peptides and proteins was recovered. Since fluorometric measurement of GSH requires previous deproteinisation, plasma and aortic tissue samples were filtered using $10 \mathrm{kD}$ spin columns (Abcam). The LTC4 ELISA was conducted using unfiltered protein solution. Protein content of all samples was measured prior to deproteinisation by the Lowry protein assay (Bio-Rad Laboratories Ltd., Hercules, USA) and GSH levels and LTC4 levels were normalised to protein concentrations.

\section{Statistical analysis}

Data are presented as mean \pm SEM. Statistical differences of continuous variables were determined using Microsoft Excel software (Microsoft, Redmond, USA) and Origin 8.0 software (OriginLab Corporation, Northampton, USA). For comparison of two groups, unpaired Student's two-sided $t$-tests was applied. $P<0.05$ was considered statistically significant.

\section{Results}

$\mathrm{MRP}^{-/-} \mathrm{LDLr}^{-/}$double knockout mice and $\mathrm{LDLr}^{-}$- controls were fed a high-fat diet for 7 weeks. Upon completion of the feeding period, mice were sacrificed and endothelial function, reactive oxygen species formation and atherosclerotic plaque burden were measured.

Genetic disruption of the MRP1 gene is associated with decreased blood pressure in atherosclerotic mice

The clinical parameters body weight, plasma cholesterol and blood glucose levels were unaf- fected by genetic disruption of the MRP1 gene, as shown in Table I. Both systolic (SBP) and diastolic blood pressure (DBP) were significantly reduced in $\mathrm{MRP1}^{-1-} \mathrm{LDLr}^{-1}$ double knockout mice compared to controls (SBP: $93 \pm 5 \mathrm{~mm} \mathrm{Hg}$ vs. 128 $\pm 4 \mathrm{~mm} \mathrm{Hg} ; n=8-12 ; p<0.001$; DBP: $56 \pm 3 \mathrm{~mm}$ $\mathrm{Hg}$ vs. $84 \pm 3 \mathrm{~mm} \mathrm{Hg} n=8-12 ; p<0.001)$. Heart rate was slightly higher in $\mathrm{MRP}^{-/-} \mathrm{LDLr}^{1-}$ double knockout mice, which did not reach statistical significance (782 \pm 23 bpm vs. $721 \pm 17$ bpm; $n=$ $8-12 ; p=0.08)$.

\section{Genetic disruption of MRP1 improves endothelial function of atherosclerotic mice}

Endothelial function was assessed in isolated aortic rings. Aortic rings were exposed to carbachol and nitroglycerine up to maximum concentrations of $10^{-4} \mathrm{M}$ (carbachol) and $10^{-5} \mathrm{M}$ (nitroglycerine), respectively. Dose-response curves are depicted in Figure 1. MRP1 ${ }^{-1-} \mathrm{LDLr}^{-1}$ double knockout mice showed significantly improved endothelial function compared to $\mathrm{LDLr}^{--}$single knockout mice. The maximum concentration of carbachol led to a decrease in vascular tension by $22 \%$ of maximum vascular tension in control mice, compared to $44 \%$ in $\mathrm{MRP}^{-/-} \mathrm{LDLr}^{/-}$double knockout mice $(0.78 \pm 0.08$ vs. $0.56 \pm 0.06, n=10$, $p=0.048)$. Maximum endothelium-independent vasorelaxation induced by nitroglycerine was similar in both groups $(0.15 \pm 0.13$ vs. $0.21 \pm 0.09$, $n=5, p=0.68)$.

\section{Genetic disruption of the MRP1 gene attenuates reactive oxygen species formation in atherosclerotic mice}

Tissue samples of the thoracic aorta were used for the assessment of reactive oxygen species formation by $\mathrm{L} 012$ chemiluminescence. Genetic disruption of the MRP1 gene led to a significant decrease in ROS formation in MRP1 $1^{-1-} \mathrm{LDLr}^{1-}$ double knockout mice compared to controls (102 $\pm 27 \mathrm{RLU} / \mathrm{s} / \mathrm{mg}$

Table I. Clinical parameters. Clinical parameters were assessed at the end of the feeding period. Body weight, plasma cholesterol and blood glucose levels, as well as heart rate, were similar in both groups. MRP1 ${ }^{-/-} \mathrm{LDLr}^{\prime-}$ double knockout mice, however, exhibited significantly reduced systolic and diastolic blood pressure compared to $\mathrm{LDLr}^{-1}$ single knockout controls

\begin{tabular}{|c|c|c|c|}
\hline Parameter & $\mathrm{LDLr}^{-1-}$ & MRP1 1/- $\mathrm{LDLr}^{-/-}$ & $P$-value \\
\hline Weight [g] & $30.4 \pm 1.0$ & $30.8 \pm 0.6$ & $>0.05$ \\
\hline Plasma cholesterol [mg/dl] & $790 \pm 25$ & $762 \pm 42$ & $>0.05$ \\
\hline Plasma glucose [mg/dl] & $101 \pm 7$ & $99 \pm 8$ & $>0.05$ \\
\hline Systolic blood pressure [mm Hg] & $128 \pm 4$ & $93 \pm 5$ & $<0.001$ \\
\hline Diastolic blood pressure [mm Hg] & $84 \pm 3$ & $56 \pm 3$ & $<0.001$ \\
\hline Heart rate $[\mathrm{bpm}]$ & $721 \pm 17$ & $782 \pm 32$ & $>0.05$ \\
\hline
\end{tabular}

Data are presented as mean \pm standard error of the mean; $n=8-12 . L D L r-l o w$-density lipoprotein receptor, MRP $1-$ multidrug resistanceassociated protein 1. 
A

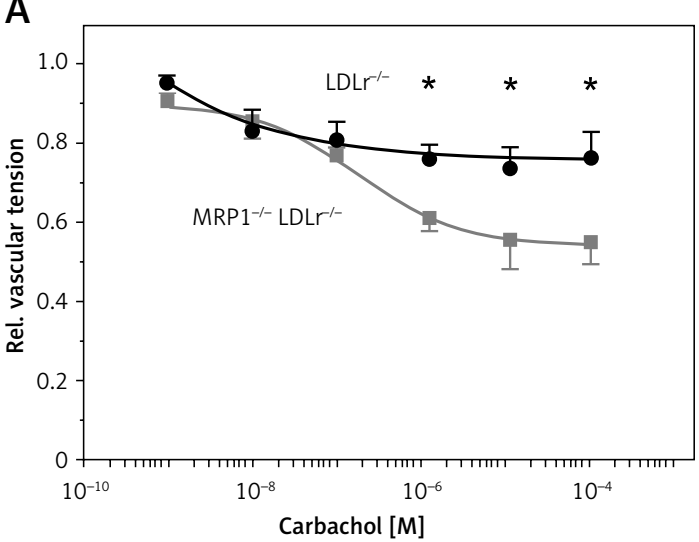

B

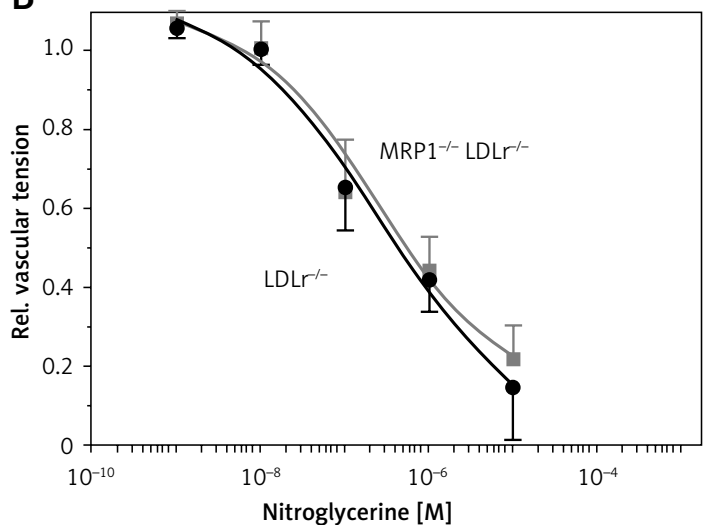

Figure 1. Dose-response curves of drug-induced vasodilation. Isolated aortic rings of MRP1 $1^{-/-} \mathrm{LDLr}{ }^{/-}$double knockout mice (grey traces) and LDLr ${ }^{-}$single knockout controls (black traces) were exposed to increasing concentrations of carbachol to measure endothelium-dependent vasorelaxation. Endothelial function was significantly improved in $\mathrm{MRP}^{-/-} \mathrm{LDLr}^{\prime-}$ double knockout mice (A). Endothelium-independent vasorelaxation, which was measured upon administration of nitroglycerine, was similar in both groups (B). Absolute vascular tension was divided by maximum vascular tension to obtain relative vascular tension

Data are presented as mean \pm standard error of the mean; $n=5-6$; ${ }^{*} p<0.05$. LDLr-low-density lipoprotein receptor, $M-$ molar, MRP1 - multidrug resistance-associated protein 1.

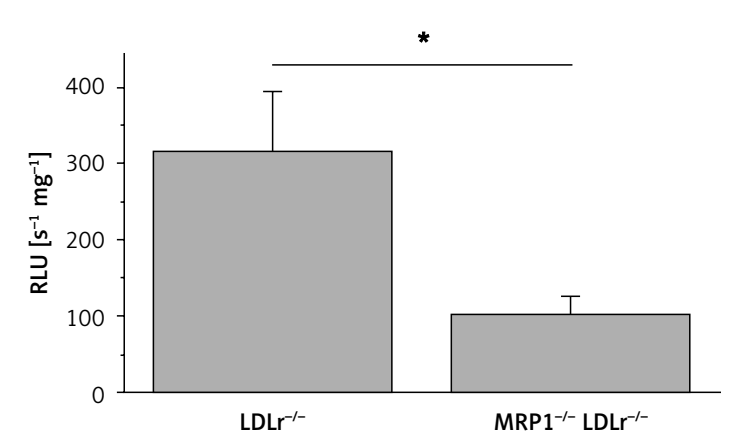

Figure 2. Measurement of reactive oxygen species formation. Reactive oxygen species were measured in aortic tissue of $\mathrm{MRP1}^{-1-} \mathrm{LDLr}^{--}$double knockout mice and $\mathrm{LDLr}^{-1}$ single knockout controls using L-012 enhanced chemiluminescence. The amount of ROS in MRP1 $1^{-/} \mathrm{LDLr}^{--}$double knockout mice was significantly lower than in $\mathrm{LDLr}^{\prime-}$ controls

Data are presented as mean \pm standard error of the mean; $n=5-6 ;{ }^{*} p<0.05 . L D L r-$ low-density lipoprotein receptor, MRP1 - multidrug resistance-associated protein 1, $R L U$ - relative light units.

vs. $315 \pm 78 \mathrm{RLU} / \mathrm{s} / \mathrm{mg}, n=9-11, p=0.03$, Figure 2).

\section{$\mathrm{MRP}^{-/-} \mathrm{LDLr}^{-/-}$double knockout mice exhibit a significant reduction in atherosclerotic plaque burden}

The atherosclerotic plaque burden was assessed by oil red staining of frozen sections through the aortic sinus and normalised to the size of the vessel wall. As depicted in Figure 3, MRP1-deficient MRP1 ${ }^{-/-} \mathrm{LDLr}^{--}$double knockout mice showed a significantly reduced plaque burden compared to $\mathrm{LDLr}^{--}$single knockout controls ( $0.06 \pm 0.01$ vs. $0.12 \pm 0.02 ; n=6 ; p=$ 0.047).

\section{MRP1-deficient mice exhibit an increase in vascular GSH- and a decrease in vascular LTC4-levels}

Aortic GSH levels of $\mathrm{MRP}^{-/-} \mathrm{LDLr}^{--}$double knockout mice were higher compared to $\mathrm{LDLr}^{-}$ single knockout controls, but the difference did not reach statistical significance $(1.02 \pm 0.23 \mathrm{nmol} / \mathrm{mg}$ protein vs. $0.71 \pm 0.13 \mathrm{nmol} / \mathrm{mg}$ protein; $n=5 ; p=$ 0.270). Meanwhile, GSH plasma levels of MRP1 ${ }^{-1-}$ $\mathrm{LDLr}^{\prime-}$ double knockout mice showed non-significantly lower levels compared to controls $(10.50$ $\pm 0.95 \mathrm{pmol} / \mathrm{mg}$ protein vs. $14.82 \pm 1.76 \mathrm{pmol} / \mathrm{mg}$ protein; $n=5 ; p=0.056)$, which illustrates the impaired efflux of GSH in MRP1-deficient mice.

In addition, aortic LTC4 levels were significantly lower in $\mathrm{MRP}^{-1-} \mathrm{LDLr}^{-1}$ double knockout mice compared to controls (724 $\pm 159 \mathrm{pg} / \mathrm{mg}$ protein vs. $1480 \pm 145 \mathrm{pg} / \mathrm{mg}$ protein; $n=5 ; p=0.008$ ), while LTC4 plasma levels were equally low in both groups (5.36 $\pm 1.11 \mathrm{pg} / \mathrm{mg}$ protein vs. $5.94 \pm 0.91$ $\mathrm{pg} / \mathrm{mg}$ protein; $n=5 ; p=0.69$ ).

\section{Discussion}

In the present study, we generated a $\mathrm{MRP}^{-/-}$ $\mathrm{LDLr}^{-1}$ double knockout mouse model in order to characterise the impact of the anion exporter MRP1 on endothelial dysfunction and atherogenesis in atherosclerotic mice.

One former study has already demonstrated that the MRP1 inhibitor MK571 leads to improved endothelial function and reduces atherosclerosis in ApoE-deficient mice [8]. Yet, one major drawback of this former approach is that MK571 also blocks the leukotriene receptor CysLT1 at low nanomolar concentrations. The CysLT1 receptor 
A

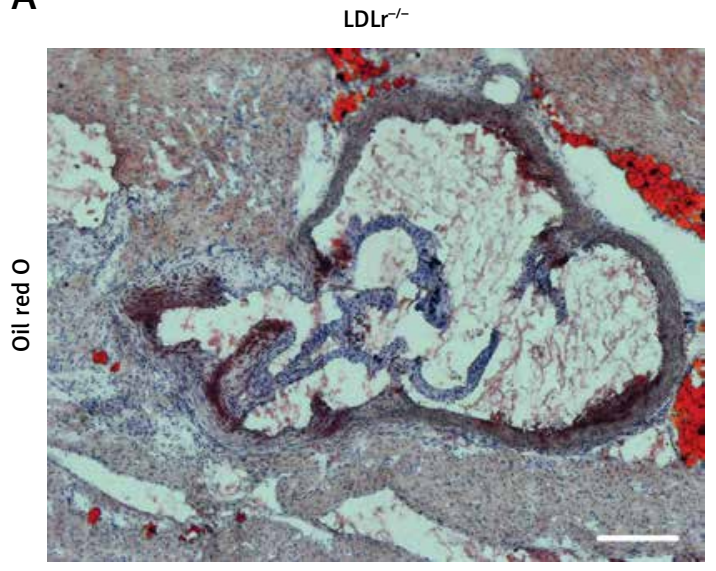

C

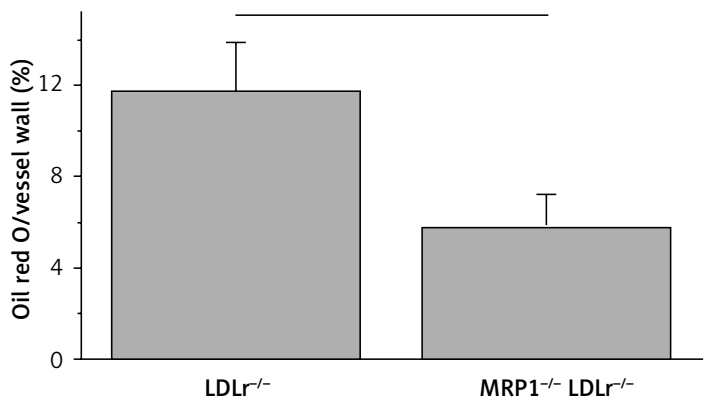

is expressed on a wide range of inflammatory cells including monocytes, macrophages, B-lymphocytes and mast cells (reviewed in [17]) and the significance of leukotriene signalling to atherosclerosis has been demonstrated in various atherosclerotic rodent models (reviewed in [18]). Thus, it remained unclear whether the atheroprotective effects of MK571 are due to MRP1 inhibition or due to blockade of CysLT1. The present study was designed to overcome these limitations of pharmacological MRP1 inhibition. By generating an MRP1-deficient and atherosclerosis-prone $\mathrm{MRP1}^{-/-} \mathrm{LDLr}^{-1}$ double knockout mouse model, we were able to selectively study the significance of MRP1 to atherogenesis without interfering with CysLT1 receptor activation.

Following a high-cholesterol diet for 7 weeks, the endothelial function of $\mathrm{MRP}^{-/-} \mathrm{LDLr}^{- \text {- }}$ double knockout mice was significantly improved compared to $\mathrm{LDLr}^{-1}$ single knockout mice. These data are in line with previous studies that connected knockout of the MRP1 gene with improved endothelial function in hypertensive mouse models [6, $10,11]$. Our present study extends our knowledge of the impact of MRP1 on endothelial dysfunction to an atherosclerotic mouse model.

Interestingly, atherosclerotic $\mathrm{MRP}^{-/-} \mathrm{LDLr}^{\prime-}$ double knockout mice exhibited significantly reduced blood pressure with a slight, but not statistically significant compensatory elevation of the
B

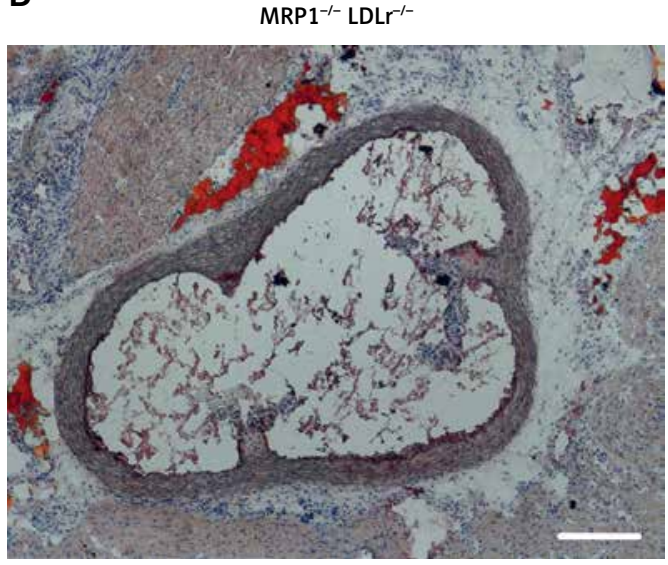

Figure 3. Assessment of atherosclerotic plaque burden. The atherosclerotic plaque burden was assessed in frozen sections through the aortic sinus and by subsequent oil red $\mathrm{O}$ staining (A, B). Total plaque volume was divided by the area of the vessel wall to produce relative plaque burden. MRP1-deficient mice exhibited a significantly reduced plaque burden compared to controls (C)

Data are presented as mean \pm standard error of the mean; $n=6$; ${ }^{*} p<0.05$. Scale bar, $200 \mu \mathrm{m}$. LDLr - lowdensity lipoprotein receptor, MRP1 - multidrug resistanceassociated protein 1.

heart rate. This supports earlier findings by Widder et al., who reported an attenuated increase in blood pressure of $\mathrm{MRP}^{-/-}$mice compared to wildtype mice upon administration of angiotensin II. As suggested by Widder et al., the disruption of MRP1 might lower arterial blood pressure by preserving vascular availability of NO [10].

In addition to an improved endothelial function, the amount of both ROS and LTC4 in the aorta of MRP1 ${ }^{-/-} \mathrm{LDLr}^{--}$double knockout mice was significantly reduced. This reduction in ROS within the vasculature matches the improved endothelial relaxation capacity, since ROS are assumed to reduce the vascular availability of NO (reviewed in $[19,20]$ ). Most recently, LTC $_{4}$ has been demonstrated to be a major driving force of ROS generation in various cell types [21]. Like GSH, LTC 4 is actively exported from cells by MRP1 [22]. Interestingly, Dvash et al. showed that $\mathrm{LTC}_{4}$ exerts its proinflammatory action via intracrine activity, since blockade of MRP1 led to an increase in cellular LTC and, subsequently, to an increase in ROS formation [21]. In the present study, genetic disruption of MRP1 led to a decrease in aortic LTC4 levels and a decrease in ROS formation, which illustrates that intracrine $\mathrm{LTC}_{4}$ activity may not be the main trigger of ROS formation in the present experimental approach. We suggest that either reduced extracellular $\mathrm{LTC}_{4}$ signalling [8] or increased intracellular GSH levels enhance cellular ability to mitigate 
ROS in the present model, which ultimately leads to improved endothelial function. The increase of cellular GSH might be due to both a reduced GSSG efflux and upregulation of GSSG reductase activity, which has already been documented for pharmacological inhibition of MRP1 [8].

Further, genetic disruption of MRP1 led to a significantly reduced atherosclerotic plaque burden. This finding matches our current understanding that excess of ROS and impaired endothelial function are initial steps of atherogenesis that ultimately culminate in atherosclerotic plaque formation $[1,23]$. The anti-atherogenic effect observed in this study might be immediately caused by the reduced amount of ROS or might be secondary to decreased blood pressure.

Taken together, our data suggest that MRP1 contributes to an increased amount of ROS and to impaired endothelial function and an increase in blood pressure with subsequent atherogenic effects in the LDLr ${ }^{\prime-}$ atherosclerotic mouse model. MRP1 appears to disturb cellular redox balance, and its specific inhibition might represent a promising strategy to improve endothelial function and to attenuate disease progression in patients suffering from atherosclerosis.

\section{Acknowledgments}

Julian Jehle and Cornelius F. H. Müller - contributed equally.

We thank Theresa Schmitz, Anna Flender and Kathrin Paul-Krahé for excellent technical assistance. This work was supported by the Bonfor program (Gerok scholarships to JJ and VT). GN is a member of the Excellence Cluster Immunosensation.

\section{Conflict of interest}

The authors declare no conflict of interest.

\section{References}

1. Harrison D, Griendling KK, Landmesser U, Hornig B, Drexler $\mathrm{H}$. Role of oxidative stress in atherosclerosis. Am J Cardiol 2003; 91: 7A-11A.

2. Li H, Horke S, Förstermann U. Vascular oxidative stress, nitric oxide and atherosclerosis. Atherosclerosis 2014; 237: 208-19.

3. Pokrywka A, Zembron-Lacny A, Baldy-Chudzik K, Orysiak J, Sitkowski D, Banach M. The influence of hypoxic physical activity on cfDNA as a new marker of vascular inflammation. Arch Med Sci 2015; 11: 1156-63.

4. Dickinson DA, Forman HJ. Glutathione in defense and signaling: lessons from a small thiol. Ann N Y Acad Sci 2002; 973: 488-504.

5. Hirrlinger J, König J, Keppler D, Lindenau J, Schulz JB, Dringen $\mathrm{R}$. The multidrug resistance protein MRP1 mediates the release of glutathione disulfide from rat astrocytes during oxidative stress. J Neurochem 2001; 76: 627-36.
6. Hirrlinger J, Schulz JB, Dringen R. Glutathione release from cultured brain cells: multidrug resistance protein 1 mediates the release of GSH from rat astroglial cells. J Neurosci Res 2002; 69: 318-26.

7. Mueller CF, Widder JD, McNally JS, McCann L, Jones DP, Harrison DG. The role of the multidrug resistance protein-1 in modulation of endothelial cell oxidative stress. Circ Res 2005; 97: 637-44.

8. Mueller CF, Wassmann K, Widder JD, et al. Multidrug resistance protein-1 affects oxidative stress, endothelial dysfunction, and atherogenesis via leukotriene C4 export. Circulation 2008; 117: 2912-8.

9. Laursen JB, Boesgaard S, Trautner S, Rubin I, Poulsen HE, Aldershvile J. Endothelium-dependent vasorelaxation in inhibited by in vivo depletion of vascular thiol levels: role of endothelial nitric oxide synthase. Free Radic Res 2001; 35: 387-94.

10. Widder JD, Guzik TJ, Mueller CF, et al. Role of the multidrug resistance protein-1 in hypertension and vascular dysfunction caused by angiotensin II. Arterioscler Thromb Vasc Biol 2007; 27: 762-8.

11. Neuser J, Fraccarollo D, Wick M, Bauersachs J, Widder JD. Multidrug resistance associated protein-1 (MRP1) deficiency attenuates endothelial dysfunction in diabetes. J Diabetes Complications 2016; 30: 623-7.

12. Mueller CF, Afzal S, Becher UM, Wassmann S, Nickenig G, Wassmann K. Role of the multidrug resistance protein-1 (MRP1) for endothelial progenitor cell function and survival. J Mol Cell Cardiol 2010; 49: 482-9.

13. Singh RK, Gupta S, Dastidar S, Ray A. Cysteinyl leukotrienes and their receptors: molecular and functional characteristics. Pharmacology 2010; 85: 336-49.

14. Hoyer FF, Steinmetz M, Zimmer S, et al. Atheroprotection via cannabinoid receptor-2 is mediated by circulating and vascular cells in vivo. J Mol Cell Cardiol 2011; 51: 1007-14.

15. Jehle J, Hoyer FF, Schöne B et al. Myeloid-specific deletion of diacylglycerol lipase alpha inhibits atherogenesis in ApoE-deficient mice. PLoS One 2016; 11: e0146267.

16. Tiyerili V, Becher UM, Camara B, et al. Impact of peroxisome proliferator-activated receptor gamma on angiotensin II type 1 receptor-mediated insulin sensitivity, vascular inflammation and atherogenesis in hypercholesterolemic mice. Arch Med Sci 2015; 11: 877-85.

17. Bäck $M$, Hansson GK. Leukotriene receptors in atherosclerosis. Ann Med 2006; 38: 493-502.

18. Bäck M. Inflammatory signaling through leukotriene receptors in atherosclerosis. Curr Atheroscler Rep 2008; 10: 244-51.

19. Landmesser U, Hornig B, Drexler H. Endothelial dysfunction in hypercholesterolemia: mechanisms, pathophysiological importance, and therapeutic interventions. Semin Thromb Hemost 2000; 26: 529-37.

20. Münzel T, Sinning C, Post F, Warnholtz A, Schulz E. Pathophysiology, diagnosis and prognostic implications of endothelial dysfunction. Ann Med 2008; 40: 180-96.

21. Dvash E, Har-Tal M, Barak S, Meir O, Rubinstein M. Leukotriene $\mathrm{C} 4$ is the major trigger of stress-induced oxidative DNA damage. Nat Commun 2015; 6: 10112.

22. Barnouin K, Leier I, Jedlitschky G, et al. Multidrug resistance protein-mediated transport of chlorambucil and melphalan conjugated to glutathione. Br J Cancer 1998; 77: 201-9.

23. Pingel S, Tiyerili V, Mueller J, Werner N, Nickenig G, Mueller C. Thrombin inhibition by dabigatran attenuates atherosclerosis in ApoE deficient mice. Arch Med Sci 2014; 10: 154-60. 